Mager, J., Kinduer, S. H. \& Grossowicz, N. (1954). J. gen. Microbiol. 10, 130-141.

\title{
Nutritional Studies with Clostridium parabotulinum Type A
}

\author{
By J. MAGER aNd S. H. KINDLER \\ Israeli Institute for Biological Research, Ness Ziona, Israel \\ AND N. GROSSOWICZ \\ Department of Bacteriology, The Hebrew University, Hadassah \\ Medical School, Jerusalem, Israel
}

\begin{abstract}
SUMMARY: The nutritional requirements of eight strains of Clostridium parabotulinum type A were studied. Five strains required for optimum growth the three vitamins, biotin, thiamine and $p$-aminobenzoic acid, one strain showed additional demands for nicotinic acid and pyridoxin, whilst two non-toxigenic strains required biotin and $p$-aminobenzoic acid. Biotin could be replaced by oleic acid and a number of Tweens, $\boldsymbol{p}$-aminobenzoic by folic acid, citrovorum factor or a mixture of thymine and purines.
\end{abstract}

All the strains tested showed good growth in a medium containing at least $2.5 \%$ casein hydrolysate (Difco), equivalent to about $0.18 \% \mathrm{~N}$. The casein hydrolysate could be replaced by a mixture of amino acids, of which the following nine were essential: tryptophan, threonine, valine, leucine, isoleucine, methionine, arginine, phenylalanine and tyrosine. The last three acids were required in unusually large amounts. Growth in chemically defined medium was followed by a rapid lysis. In spite of optimum growth, the toxin titre in the defined medium was about 50,000 $\mathbf{L D}_{50}$ doses/ml., i.e. approximately ten times less than that obtained in complex media.

The cultivation of spore-forming anaerobic bacteria (Clostridium sporogenes) in chemically defined media was first attempted by Knight \& Fildes (1933). In the following years, defined media for a number of other anaerobic sporeforming species were elaborated (Brown, Wood \& Werkman, 1939; McDaniel, Woolley \& Peterson, 1939; Weizmann \& Rosenfeld, 1939; Rubbo \& Gillespie, 1940; Lampen \& Peterson, 1944; Feeney, Mueller \& Miller, 1943; Bernheimer, 1944; Boyd, Logan \& Tytell, 1948; Smith, L. DeSpain \& Douglas, 1950). Investigations of the growth requirements of $\mathrm{Cl}$. botulinum which started quite early (Hosoya \& Kishino, 1925; Burrows, 1933; Fildes, 1935) did not lead to the complete elucidation of the factors involved. Elberg \& Meyer (1939), summing up earlier literature and corroborating the results of Fildes \& Richardson (1935), concluded that $\mathrm{Cl}$. botulinum could be cultivated in a defined medium consisting of ten amino acids, citrate and the unidentified 'sporogenes vitamin' of Knight \& Fildes (1933). Pappenheimer (1935) did not succeed in identifying this vitamin; later studies showed it to be not a single chemical entity but to consist of a mixture of several vitamins of the $\mathbf{B}$ group. Thus, in the case of $\mathrm{Cl}$. sporogenes, Shull \& Peterson (1948) were able to replace the 'sporogenes factor' by a mixture of biotin, $p$-aminobenzoic $(p-\mathrm{AB})$ and nicotinic acid.

With $\mathrm{Cl}$. botulinum Lamanna \& Lewis (1946) replaced the 'sporogenes 
factor' by the following six vitamins: biotin, thiamine, folic acid, calcium pantothenate, choline and pyridoxin. Roessler \& Brewer (1946) claimed, on the other hand, that biotin, $p-\mathbf{A B}$, nicotinamide, riboflavine and nucleic acid (or its components) were required. As the reports of the last-mentioned groups of investigators are conflicting and of a rather qualitative nature, it was thought worth while to re-investigate the problem.

\section{MATERIALS AND METHODS}

Chemicals. Substances used were obtained from the following sources: vitamins from Hoffman LaRoche (Basel) or National Biochemicals Corporation (NBC).

Citrovorum Factor (CF): Leucovorin calcium salt, kindly supplied by Dr H. P. Broquist of the Lederle Laboratories. Biocytin, through the courtesy of Dr L. D. Wright of Sharp and Dohme Co., Michigan. The synthetic pyrimidine moiety of thiamine (2-methyl-5-ethoxymethyl-6-aminopyrimidine) and the synthetic thiazole moiety of thiamine (4-methyl-5-hydroxyethyl thiazole) from Merck. Casein hydrolysate (CH), Casamino acids Vitamin Free (Difco) or Casein Hydrolysate Vitamin Free 10\% soln. (NBC). Sodium mercaptoacetate (thioglycollate; NBC). All other chemicals were of A.R. grade.

Glassware. All glassware was cleaned with chromic + sulphuric acid mixture, washed with running tap water, and finally rinsed three times with twice glass-distilled water.

Media. All media were derived from the following basal medium, which contained, for each litre; glucose, 5 g.; tryptophan, 50 mg.; cysteine, 250 mg.; $\mathrm{Na}$ mercaptoacetate, $500 \mathrm{mg}$; ; salts A soln. (Snell, Strong \& Peterson, 1937), $10 \mathrm{ml}$.; salts B (Snell et al. 1937), 1.0 ml.; the pH was adjusted to $7 \cdot 4$. Double-strength medium was dispensed into matched test tubes plugged with cotton-wool. Wrapping the cotton plugs with cellophan or replacing them by metal caps did not affect the results.

Sterilization was effected by autoclaving for $15 \mathrm{~min}$. at $15 \mathrm{lb} . / \mathrm{sq} . \mathrm{in}$. Glucose, vitamins and other substances were sterilized by Seitz filtration and added aseptically to the basal medium. The volume in each tube was then made up to $10 \mathrm{ml}$. with double-distilled water. The tubes were heated in a boilingwater bath for $10 \mathrm{~min}$., cooled to room temperature and inoculated immediately. All experiments were run in duplicate.

Strains and inocula. Experiments were carried out with the following strains: strain 1, National Collection of Type Cultures, NCTC 3811 (Hall); strain 2, obtained from the Hebrew University, Jerusalem; strain 3, NCTC 7272 (Porton); strain 4, American Type Culture Collection (ATCC) 441; strain 5, ATCC 687; strain 6, ATCC 3502 (Hall); strain 7, ATCC 7948; strain 8, NCTC 2916. Stock cultures were carried in cooked meat broth or in Brewer's anaerobic medium (Difco). Inoculations into the defined medium were made from $24 \mathrm{hr}$. cultures; $0.1 \mathrm{ml}$. was added to each tube. In some experiments the inoculum was washed 3 times with saline containing $0.05 \%(w / v) ~ N a$ mercaptoacetate and diluted $1 / 100$ with the same solution. Usually, however, washing was omitted because of its harmful effect on viability. Carry-over of growth 
factors could be eliminated by serial transfers. In a few instances a washed suspension of spores was used as inoculum. Spore suspensions were obtained by growing the organisms in brain-heart medium (Difco) for 5 days, and heating the culture at $70^{\circ}$ for $30 \mathrm{~min}$.; the spores were then centrifuged down and washed with mercaptoacetate-saline.

Incubation. The tubes after inoculation were incubated at $34^{\circ}$ in anaerobic jars (McIntosh \& Fildes), evacuated by a vacuum pump and refilled with hydrogen. In some experiments $0.01 \%$ sodium bicarbonate was added to the medium to ensure adequate supply of $\mathrm{CO}_{2}$, but under our conditions only a slight, if any, effect of this addition was noticed.

Estimation of growth. Growth was usually estimated by measurement of turbidity with a junior Coleman Spectrophotometer at $450 \mathrm{~m} \mu$. and expressed either in terms of percentage transmission or as optical density. In some experiments the turbidimetric results were correlated with viable counts. The counts were made in Brewer's anaerobic agar (Baltimore Biological Laboratories, Maryland, U.S.A.) and the Petri dishes incubated in anaerobic jars.

Assay of toxin. Toxin production was usually tested after growth for 5 days in a medium similar to that used by Lewis \& Hill (1947). Results were calculated in terms of $\mathrm{LD}_{50}$ according to the method of Reed \& Muench (1938).

\section{RESULTS}

\section{Nitrogen requirement}

Attempts to grow $\mathrm{Cl}$. parabotulinum type $\mathrm{A}$ in media containing $\mathbf{0 . 5} \%$ (w/v) casein hydrolysate, as recommended by Lamanna \& Lewis (1946), were unsuccessful even when the number of growth factors added included all the known $B$ complex. Growth if any was irregular and scanty. In order to test the possibility that lack of growth was due to the inadequate supply of some amino acids, the effect of increasing concentrations of casein hydrolysate was tried. The experiments showed that optimal growth of all strains could be obtained only at a level of $2.5 \%(\mathrm{w} / \mathrm{v})$ casein hydrolysate, providing $17.5 \mathrm{mg}$. $\mathrm{N} / 10 \mathrm{ml}$. medium. This concentration of casein hydrolysate was therefore used in all further work. Since these results suggested that some amino-acids might be required in unusually large amounts, we tried the effect of adding excess of amino-acids, in groups of 1-19, to the basal medium containing $0.5 \%$ casein hydrolysate. Of the nineteen amino-acids tested, the combination arginine $(30 \mathrm{mg} . / 10 \mathrm{ml}$.) and phenylalanine $(20 \mathrm{mg} . / 10 \mathrm{ml}$.) and tyrosine $(2.5 \mathrm{mg} . / 10 \mathrm{ml}$.) yielded growth exceeding that in a medium containing $\mathbf{2 . 5} \%$ casein hydrolysate. Although tyrosine and phenylalanine substituted for each other to some extent, both were essential and maximum growth was obtained only when both were present in relatively large concentrations. Arginine could be replaced more or less adequately by ornithine or lysine.

\section{Amino acid requirements}

In order to arrive at a fully defined medium, casein hydrolysate was replaced by the following mixture of nineteen amino acids: L-arginine, DL-phenylalanine, L-tyrosine, L-tryptophan, DL-leucine, DL-isoleucine, DL-valine, DL- 
threonine, DL-methionine, L-histidine, DL-lysine, DL-alanine, L-proline, DL-serine, DL-glutamic acid, DL-aspartic acid, L-hydroxyproline, glycine and L-cysteine. The concentrations used are shown in Table 1. Further experiments showed the following nine amino acids to be essential: L-arginine, DL-phenylalaline, L-tyrosine, DL-leucine, DL-isoleucine, DL-valine, L-tryptophan, DL-threonine and DL-methionine (Table 1). These findings are in agreement with the results of Roessler \& Brewer (1946).

\section{Table 1. Amino acid requirements of $\mathrm{Cl}$. parabotulinum type $A$}

Representative values for strains 1 to 8 .

Basal medium with biotin, thiamine and $p-\mathrm{AB}$ added. Nineteen amino acids $(\mathrm{mg} . / 10 \mathrm{ml}$.): L-arginine 30, DL-phenylalanine 20, L-tyrosine 2.5, DL-valine 20, DL-leucine 15, DL-isoleucine 5, L-tryptophan 0.5, oL-threonine 10, DL-methionine 6, L-proline 4.5, L-hydroxyproline 1, L-histidine 2, DL-glutamic acid 10, DL-aspartic acid 9, DL-lysine 12, DL-alanine $4 \cdot 2$, DL-serine 10, L-cysteine $2 \cdot 5$, glycine 1 .

Nine amino acids (mg./10 ml.): L-arginine 30, DL-phenylalanine 20, L-tyrosine 2.5, DL-valine 20, DL-leucine 15, DL-isoleucine 5, L-tryptophan 0.5, DL-threonine 10, DLmethionine 6.

\begin{tabular}{lr}
\multicolumn{1}{c}{ N source } & $\begin{array}{r}\% \\
\text { after } 24\end{array}$ \\
19 Amino acids & 23 \\
9 Amino acids & 32 \\
Amino acid omitted & \\
from mixture of 9 & \\
L-arginine & 100 \\
DL-phenylalanine & 88 \\
L-tyrosine & 100 \\
DL-valine & 90 \\
DL-leucine & 55 \\
DL-isoleucine & 76 \\
L-tryptophan & 94 \\
DL-threonine & 84 \\
DL-methionine & 80 \\
DL-leucine and DL-isoleucine & 100
\end{tabular}

The mixture of nine amino acids gave consistently good growth, which was, however, somewhat inferior to that obtained with the mixture of nineteen amino acids. It seems, therefore, that the remaining amino-acids had some adjuvant effect. Methionine could be partially replaced by cysteine, but full growth was not obtained when cysteine alone was present. Leucine and isoleucine substituted for each other to some extent.

\section{Vitamin requirements}

To determine the vitamins required for optimum growth, one vitamin at a time was omitted from an otherwise complete medium containing initially six vitamins. The results of these experiments are summarized in Table 2.

When 'Casamino acids' (Difco) was used as a source of nitrogen, it appeared that biotin and thiamine were the only essential growth factors. Slight growth was consistently obtained with biotin as the only vitamin added; $p$-AB seemed only to be stimulatory. On the other hand, when the source of amino acids was a casein hydrolysate prepared in our laboratory (by autoclaving casein 
with sulphuric acid and removal of vitamins by adsorption with 'Norit $\mathbf{A}$ ' charcoal) an absolute requirement for $p-\mathrm{AB}$ was found. It appeared therefore that Difco casein hydrolysate contained small amounts of $p$-AB or a substance possessing similar biological activity. The essential requirement for these three vitamins was further confirmed when a completely defined medium containing a mixture of amino acids in place of casein hydrolysate was used (Table 2).

\section{Table 2. Effect of vitamins on growth of $\mathrm{Cl}$. botulinum type $\mathrm{A}$}

C.H. (Difco) $=$ Casamino acids Difco 'vitamin-free'.

CHS = Sulphuric acid hydrolysate of casein, 'Norit' adsorbed (17.5 mg. N/10 ml.).

Amino acid mixture: nine amino acids, see Table 1.

Sixteen vitamins: $(\mu \mathrm{g} . / 10 \mathrm{ml}$.) Biotin, 0.005 ; thiamine, 4 ; folic acid, 0.1; choline, 25 ; Ca-pantothenate, 10 ; pyridoxin, 5 ; pyridoxamine, 5 ; pyridoxal $\mathrm{HCl}, 5$; pyridoxal phosphate, 5 ; nicotinic acid, 10 ; nicotinamide, 10 ; riboflavin, 5 ; inositol, 400 ; citrovorum factor, $0 \cdot 1$; $p-\mathrm{AB}, 0.1 ; \mathrm{B}_{12}, 0.5$.

Six vitamins: $(\mu \mathrm{g} . / 10 \mathrm{ml}$.) biotin, 0.005 ; thiamine, 4 ; folic acid, 0.1 ; choline, 25 ; Capantothenate, 10; pyridoxine, 5.

Five vitamins: $(\mu \mathrm{g} . / 10 \mathrm{ml}) p-.\mathrm{AB}, 0 \cdot 1$; nicotinamide, 10 ; riboflavin, 5 ; yeast nucleic acid, 200; biotin, $0 \cdot 005$.

\begin{tabular}{|c|c|c|c|c|c|}
\hline \multirow{3}{*}{$\begin{array}{l}\text { N source } \\
\text { C.H. (Difco) } \\
\mathbf{2 . 5} \% \mathbf{w} / \mathrm{v}\end{array}$} & \multirow{2}{*}{$\begin{array}{l}\text { Vitamins added to } \\
\text { basal medium } \\
16 \text { vitamins }\end{array}$} & \multicolumn{4}{|c|}{$\%$ Transmission } \\
\hline & & 55 & 32 & 45 & 82 \\
\hline & 6 vitamins & 90 & 34 & 37 & 60 \\
\hline & 5 vitamins & 92 & 90 & 87 & 85 \\
\hline & Biotin, thiamine, $p$-AB & 71 & 34 & 37 & 61 \\
\hline & Biotin, thiamine & 92 & 72 & 60 & 40 \\
\hline & Biotin, $p$-AB & 92 & 90 & 90 & 84 \\
\hline & Biotin, Ca-pantothenate & 98 & 90 & 86 & 84 \\
\hline & Thiamine, $p$-AB & 100 & 100 & 100 & 100 \\
\hline & Biotin & 98 & 85 & 82 & 82 \\
\hline \multirow[t]{3}{*}{ CHS } & Biotin & 97 & - & - & 70 \\
\hline & Biotin, thiamine & 96 & - & - & 65 \\
\hline & Biotin, thiamine, $p$-AB & 35 & 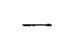 & - & 87 \\
\hline \multirow{4}{*}{$\begin{array}{l}\text { Amino acid } \\
\text { mixture }\end{array}$} & Biotin & 90 & - & - & 85 \\
\hline & Biotin, thiamine & 94 & - & - & 80 \\
\hline & Biotin, thiamine, $p-\mathrm{AB}$ & 37 & - & - & 82 \\
\hline & Biotin, $p$-AB & 92 & - & - & 84 \\
\hline
\end{tabular}

The growth response to each essential vitamin was determined as illustrated in Figs. 1 and 2. No change in nutritional or other properties of the organism was observed even after fifty serial transfers in the defined medium.

$p$-AB, citrovorum factor and folic acid were interchangeable (Fig. 2). Folic acid appeared to be the least active compound. This observation would imply that folic acid was not an intermediary in the biosynthesis of the final cofactor from $p$-AB (cf. Woods, 1952). Once an absolute requirement for the three vitamins had been established, their substitution was attempted by substances known to have similar physiological action. From Table 3 it can be seen that the requirement for biotin could be met by sodium oleate and several 'Tweens'. In this respect $\mathrm{Cl}$. botulinum behaved similarly to $\mathrm{Cl}$. sporogenes as observed by Shull, Thoma \& Peterson (1949). The thiazole 
moiety of thiamine was as effective as the whole molecule, indicating that this organism is capable of synthesizing the vitamin from the thiazole derivative.

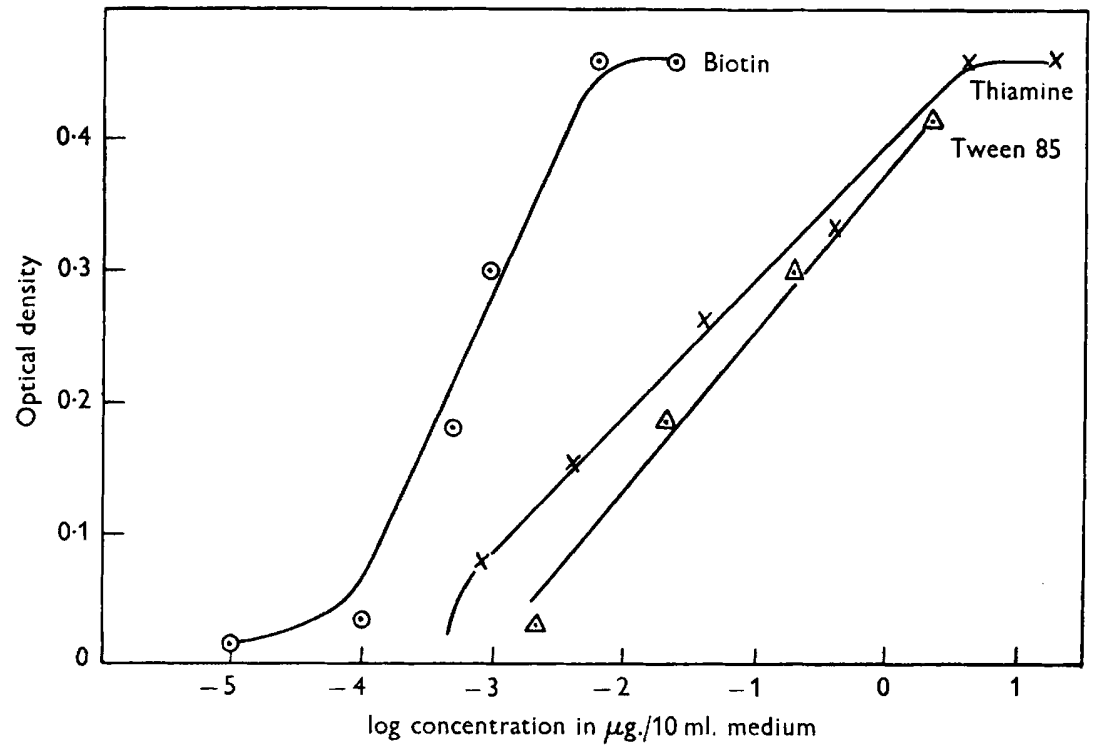

Fig. 1. Growth response of $\mathrm{Cl}$. parabotulinum type $\mathbf{A}$ (strain 1 ) to various concentrations of biotin, thiamine and Tween 85 .

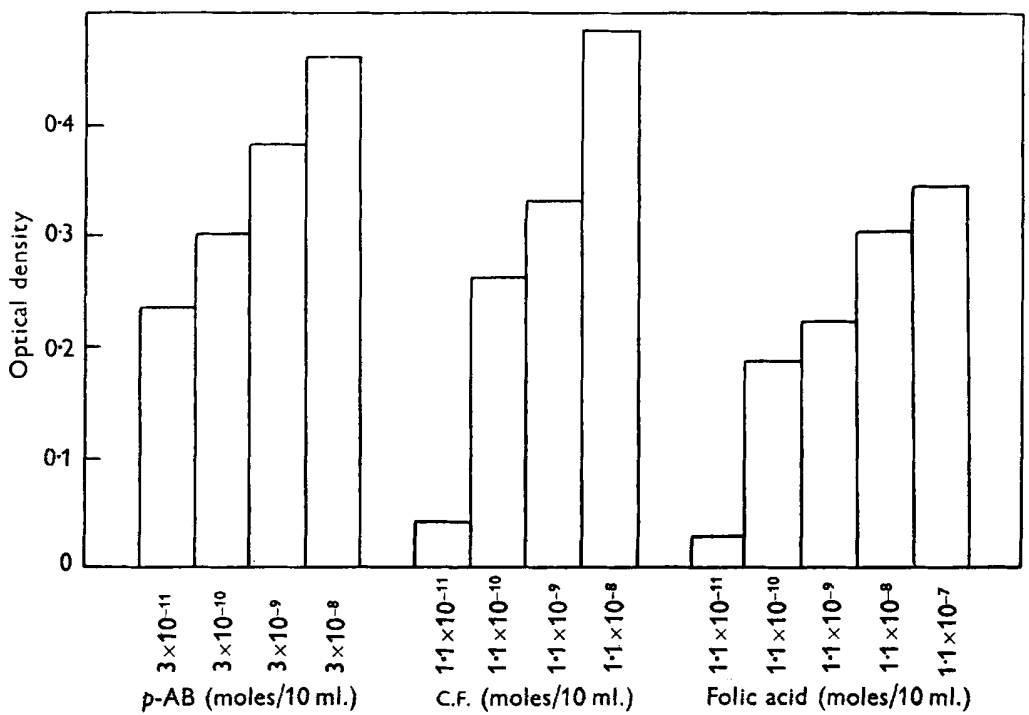

Fig. 2. Comparison of growth responses of $\mathrm{Cl}$. parabotulinum type A (strain 1 ) to various concentrations of $p-\mathrm{AB}$, citrovorum factor (CF) and folic acid.

The fact that $p-\mathrm{AB}$ could be replaced not only by folic acid and the citrovorum factor, but also by a mixture of adenine and thymine, is compatible with the view that $p-\mathrm{AB}$ serves as a precursor of a coenzyme involved in the synthesis of the latter substances (cf. Woods, 1952). 
Table 3. Replacement of vitamins by substances of similar physiological activity in nutrition of strains 1 and $\mathbf{2}$

Sulphuric acid hydrolysate of casein, 'Norit'-adsorbed (17.5 mg. N/10 ml.), was added to the basal medium.

Vitamin added to basal medium ( $\mu \mathrm{g} . / 10 \mathrm{ml}$.)

Biotin, $0 \cdot 005$; thiamine, $4 ; p$-AB, $0 \cdot 1$

Biotin, 0.005; thiamine, 4 ; folic acid, $0 \cdot 1$

Biotin, 0.005; thiamine, 4; citrovorum factor, $0 \cdot 1$

Biotin, 0.005; thiamine, $4 ; \mathrm{B}_{12}, 0 \cdot 1$

Biotin, 0.005; thiamine, 4 ; thymine, 200

Biotin, 0.005; thiamine, 4 ; thymine, $200+$ adenine, 200

Biotin, 0.005; thiamine, 4; thymidine, 200

Biotin, 0.005; thiamine, 4; thymidine, 200 +adenine, 200

Biotin, 0.005; thiamine, 4; yeast nucleic acid, 200

Biotin, 0.005; thiamine, 4; thymus nucleic acid, 200

Biotin, 0.005; thiazole of thiamine, 2, $p$-AB, 0.1

Biotin, 0.005; pyrimidine of thiamine, $2 ; p-\mathrm{AB}, 0.1$

$\mathrm{Na}$ Oleate, 1000 ; thiamine, $4 ; p$-AB, $0 \cdot 1$

Tween 80, 2000; thiamine, $4 ; p-\mathrm{AB}, 0 \cdot 1$

Tween 81, 2000; thiamine, $4 ; p-\mathrm{AB}, 0 \cdot 1$

Tween 85, 2000; thiamine, $4 ; p-\mathrm{AB}, 0 \cdot 1$

Tween 40, 2000; thiamine, $4 ; p-\mathrm{AB}, 0 \cdot 1$

Tween 60, 2000; thiamine, $4 ; p$-AB, $0 \cdot 1$

Pimelic acid, 10; thiamine, $4 ; p-\mathrm{AB}, 0 \cdot 1$

Biocytin, 0.01; thiamine, $4 ; p-\mathrm{AB}, 0 \cdot 1$
$\%$ Transmission after $38 \mathrm{hr}$.

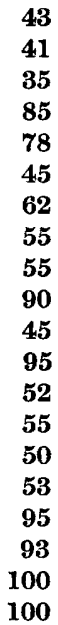

43

41

35

85

78

45

62

55

55

90

45

95

52

55

50

53

95

93

100

\section{Comparison of the vitamin requirements of various} strains of $\mathrm{Cl}$. parabotulinum type $A$

From the results summarized in Table 4 it can be seen, that of the eight strains examined, five showed identical requirements for the three vitamins biotin, thiamine and $p$-AB. Strain 8 was more exacting and required in addition pyridoxin and nicotinic acid. The identity of the toxin of strain 8 with the serological type A was confirmed by the positive outcome of a neutralization test with a specific anti-A serum obtained from the Pasteur Institute, Garches. Strains 4 and 5 did not require thiamine; furthermore, they did not produce any toxin and differed morphologically from the other strains; their growth on solid media was of the rough $(R)$ rhizoid type resembling closely the growth of $\mathrm{Cl}$. sporogenes. As there is no certain way of differentiating between Cl. sporogenes and non-toxigenic strains of $\mathrm{Cl}$. botulinum by the usual cultural or biochemical methods, it cannot be decided whether these strains represent non-toxigenic mutants of $\mathbf{C l}$. parabotulinum type $\mathbf{A}$ or are identical with $\boldsymbol{C l}$. sporogenes and were incorrectly classified as $\mathrm{Cl}$. botulinum type $\mathrm{A}$. In this connexion it should be recalled that the usual growth factors of most strains of $\mathrm{Cl}$. sporogenes are biotin and $p$-AB, while nicotinic acid is only stimulatory (Shull \& Peterson, 1948; Mager, unpublished results).

The claim of Lamanna \& Lewis (1946) that thiamine and choline can be replaced by calcium pantothenate was not borne out by our results. As can be seen from Table 2, choline had no effect at all on growth, whereas (Table 4) pantothenate did not replace thiamine for any of the strains tested. 
Table 4. Comparison of various strains of $\mathrm{Cl}$. parabotulinum type $A$ in respect of vitamin requirements

Sulphuric acid hydrolysate of casein, 'Norit'-adsorbed (17.5 mg. N/10 ml.), was added to basal medium.

Vitamins $(\mu \mathrm{g} . / 10 \mathrm{ml}$.$) : biotin, 0.005$; thiamine, $4 ; p-\mathrm{AB}, 0.1$; calcium pantothenate, 10 ; pyridoxin, 10 ; nicotinic acid, 10.

\begin{tabular}{|c|c|c|c|}
\hline Strain & $\mathbf{L D}_{\mathbf{5 0}} / \mathrm{ml}$ & Vitamins added to basal medium & $\begin{array}{l}\% \text { Transmission } \\
\text { after } 25 \mathrm{hr} .\end{array}$ \\
\hline 1 & 500,000 & $\begin{array}{l}\text { Biotin } \\
\text { Biotin, } p \text {-AB } \\
\text { Biotin, } p \text {-AB, thiamine } \\
\text { Biotin, } p \text {-AB, Ca-pantothenate }\end{array}$ & $\begin{array}{l}96 \\
97 \\
37 \\
96\end{array}$ \\
\hline 2 & 500,000 & $\begin{array}{l}\text { Biotin } \\
\text { Biotin, } p-\mathrm{AB} \\
\text { Biotin, } p \text {-AB, thiamine } \\
\text { Biotin, } p-\mathrm{AB} \text {, Ca-pantothenate }\end{array}$ & $\begin{array}{l}94 \\
94 \\
42 \\
95\end{array}$ \\
\hline $\mathbf{3}$ & 500,000 & $\begin{array}{l}\text { Biotin } \\
\text { Biotin, } p \text {-AB } \\
\text { Biotin, } p \text {-AB, thiamine } \\
\text { Biotin, } p \text {-AB, Ca-pantothenate }\end{array}$ & $\begin{array}{l}92 \\
90 \\
45 \\
89\end{array}$ \\
\hline 4 & $\mathbf{0}$ & $\begin{array}{l}\text { Biotin } \\
\text { Biotin, } p \text {-AB } \\
\text { Biotin, } p \text {-AB, thiamine } \\
\text { Biotin, } p \text {-AB, Ca-pantothenate }\end{array}$ & $\begin{array}{l}76 \\
42 \\
40 \\
42\end{array}$ \\
\hline 5 & $\mathbf{0}$ & $\begin{array}{l}\text { Biotin } \\
\text { Biotin, } p-\mathrm{AB} \\
\text { Biotin, } p \text {-AB, thiamine } \\
\text { Biotin, } p-\mathrm{AB} \text {, Ca-pantothenate }\end{array}$ & $\begin{array}{l}82 \\
41 \\
41 \\
43\end{array}$ \\
\hline $\mathbf{6}$ & 300,000 & $\begin{array}{l}\text { Biotin } \\
\text { Biotin, } p \text {-AB } \\
\text { Biotin, } p \text {-AB, thiamine } \\
\text { Biotin, } p \text {-AB, Ca-pantothenate }\end{array}$ & $\begin{array}{l}94 \\
95 \\
55 \\
94\end{array}$ \\
\hline 7 & 500,000 & $\begin{array}{l}\text { Biotin } \\
\text { Biotin, } p \text {-AB } \\
\text { Biotin, } p \text {-AB, thiamine } \\
\text { Biotin, } p-\mathrm{AB} \text {, Ca-pantothenate }\end{array}$ & $\begin{array}{l}93 \\
95 \\
44 \\
92\end{array}$ \\
\hline 8 & 200,000 & $\begin{array}{l}\text { Biotin } \\
\text { Biotin, } p \text {-AB } \\
\text { Biotin, } p-\mathbf{A B} \text {, thiamine } \\
\text { Biotin, } p-\mathbf{A B} \text {, Ca-pantothenate } \\
\text { Biotin, } p \text {-AB, thiamine, pyridoxin, } \\
\text { nicotinic acid }\end{array}$ & $\begin{array}{l}95 \\
98 \\
85 \\
95 \\
31\end{array}$ \\
\hline \multicolumn{4}{|c|}{ Size of inoculum } \\
\hline \multicolumn{4}{|c|}{$\begin{array}{l}\text { In order to test the nutritional adequacy of the defined medium, we deter } \\
\text { ined the minimum number of cells capable of initiating growth. Viabl } \\
\text { ounts indicated that an inoculum containing as few as ten vegetative cell } \\
\text { as sufficient to start growth, provided that dilutions were made in the basa } \\
\text { ledium; when saline was used as diluent the viability of the inoculum wa } \\
\text { onsiderably decreased. This threshold value compares favourably with tha } \\
\text { btained with more complex media. Similar results were obtained with } \\
\text { ashed spores. }\end{array}$} \\
\hline
\end{tabular}




\section{Effect of glucose}

In a medium containing $2.5 \%$ casein hydrolysate supplemented with arginine, phenylalanine and tyrosine, omission of glucose resulted in only slightly inferior growth. On the other hand, growth in the unsupplemented medium was much poorer when glucose was absent.

\section{Mineral requirements}

Marked depression of growth was observed when depletion of trace minerals was effected by treating the medium with $\mathrm{Al}_{2} \mathrm{O}_{3}$ as described by Donald, Passey \& Swaby (1952). Full growth was restored when mixtures of minerals were added; the effects are shown in Table 5 .

Table 5. Effect of salts on growth of Cl. parabotulinum type $A$ (strains 1 and 2)

2.5 \% (w/v) C.H. (Difco) added to basal medium, from which salts were omitted. This medium as well as glucose soln. was treated with $\mathrm{Al}_{2} \mathrm{O}_{3}$ in order to remove traces of salts.

Vitamins added $(\mu \mathrm{g} . / 10 \mathrm{ml}$.$) : biotin, 0 \cdot 005$; thiamine, $4 ; p-\mathrm{AB}, 0 \cdot 1$.

Salts A (Snell et al. 1937); Salts B (Snell et al. 1937); Salts C ( $\mu \mathrm{g} . / 10 \mathrm{ml}$.): $\mathrm{ZnSO}_{4} .7 \mathrm{H}_{2} \mathrm{O}, 80$; $\mathrm{CuSO}_{4} .5 \mathrm{H}_{2} \mathrm{O}, 45 ; \mathrm{CoCl}_{2}, 90 ; \mathrm{CaCl}_{2} .2 \mathrm{H}_{2} \mathrm{O}, 60 ; \mathrm{Na}_{2} \mathrm{~B}_{4} \mathrm{O}_{7} .10 \mathrm{H}_{2} \mathrm{O}, 140 ;\left(\mathrm{NH}_{4}\right)_{2} \mathrm{MoO}_{4}, 25$.

\begin{tabular}{lc}
\multicolumn{1}{c}{ Salts added } & $\begin{array}{c}\text { \% Transmission } \\
\text { after } 48 \mathrm{hr} .\end{array}$ \\
Salts A & $\mathbf{8 7}$ \\
Salts A and B & $\mathbf{7 3}$ \\
Salts A, B and C & $\mathbf{5 9}$ \\
& $\mathbf{4 1}$
\end{tabular}

\section{Autolysis}

Cultures of $\mathrm{Cl}$. parabotulinum in defined media exhibited a tendency to lyse rapidly. The autolysis was not related to sporulation and could be so pronounced as to result in complete sterilization of the culture. This property complicated seriously the estimation of maximum growth and made it necessary to determine growth curves as a function of time, for every set of conditions.

From Figs. 3 and 4 it can be deduced that most rapid lysis occurred under optimal conditions of growth, whereas when the vitamin supply was suboptimal the rate of autolysis was much slower. It appears, therefore, that the formation of autolytic enzymes depends on an adequate supply of certain nutrilites. As shown in Fig. 4, the rate of autolysis increased also with the rise of the initial $\mathrm{pH}$ value of the medium, from $\mathrm{pH} 6.5$ to $7 \cdot 8$. Here again the more rapid the growth the steeper the decline caused by autolysis.

\section{Toxin production}

The production of toxin in the defined medium was relatively low as compared with yields in more complex media. For instance the usual titre in the medium of Lewis \& Hill (1947) for the majority of strains of type A 


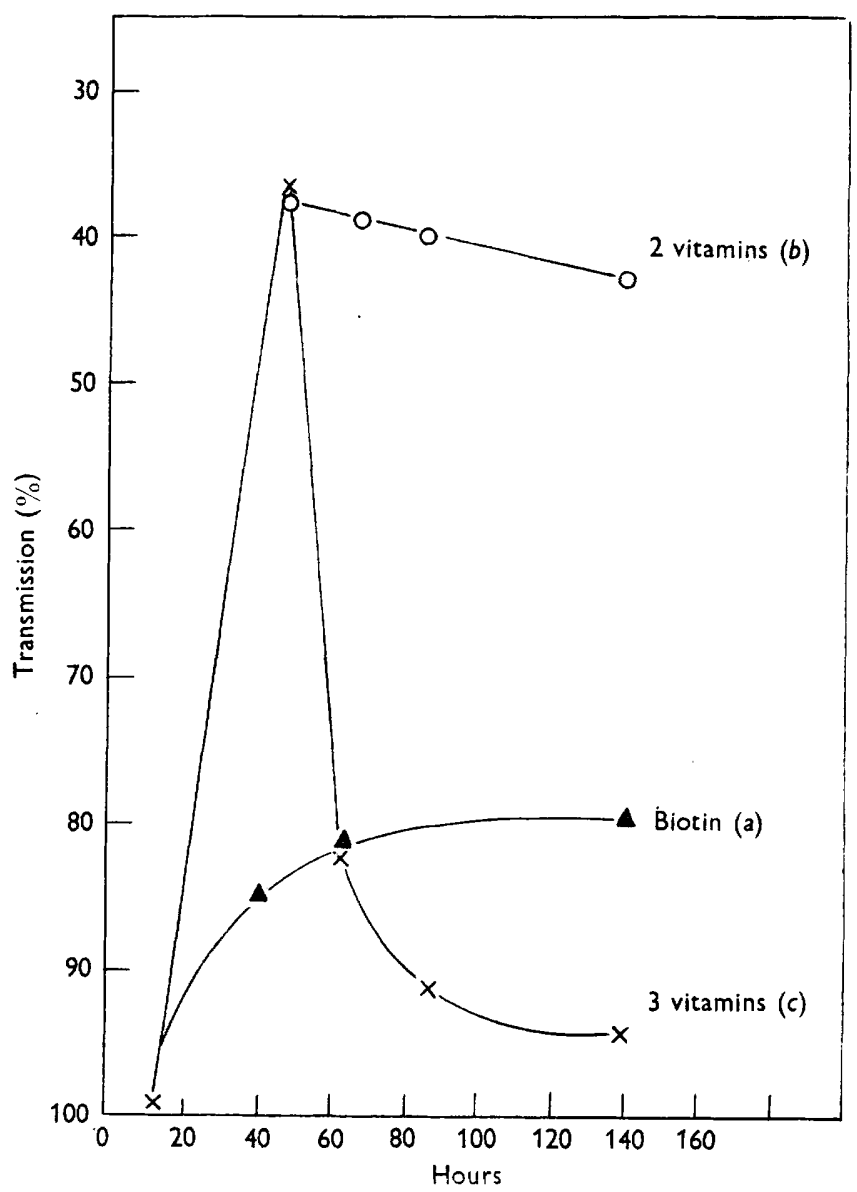

g. 3. Growth and lysis of $\mathrm{Cl}$. parabotulinum type A (strain 1 ) in media containing:

(a) biotin; (b) biotin and thiamine; (c) biotin, thiamine and $p-\mathrm{AB}$.

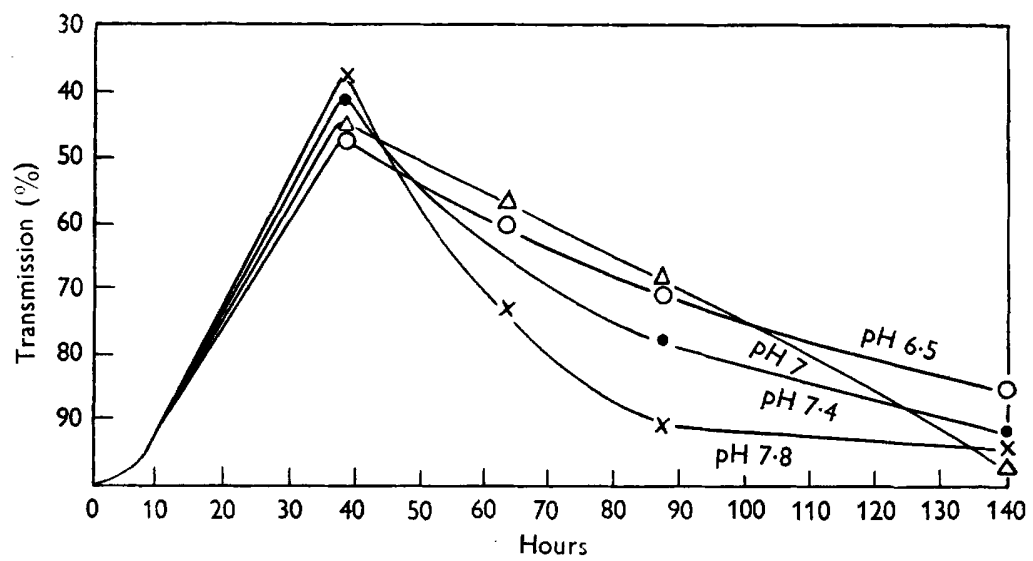

Fig. 4. Effect of the initial $\mathrm{pH}$ of the defined medium on the rate of growth and lysis of $\mathrm{Cl}$. parabotulinum type A (strain 1). 
varied between $500,000 \mathrm{LD}_{50}$ doses $/ \mathrm{ml}$. and $1,500,000 \mathrm{LD}_{50}$ doses $/ \mathrm{ml}$., whereas. in our defined medium the maximum titre obtained was usually below $50,000 \mathrm{LD}_{50}$ doses/ml. Evidently factors different from those that determine growth regulate the yield of toxin in the culture medium. An account of an investigation of the nature of these factors will form the subject of a separate communication.

\section{DISCUSSION}

Our results differ in many points from those reported by Lamanna \& Lewis (1946), and by Roessler \& Brewer (1946). The preliminary nature of the reports of these authors does not permit a thorough discussion of the reasons for these discrepancies. It seems unlikely, however, that strain variations could account for all the differences noted, as none of the eight strains examined by us conformed in their growth requirements to those described by the above authors. In this connexion it should be pointed out that $\mathrm{Cl}$. parabotulinum type $\mathbf{A}$, in the light of our results, appears to be a rather homogeneous group since out of six toxin-producing strains, five showed identical requirements for these vitamins and only one strain differed in demanding two additional vitamins. Of particular interest is the fact that, whereas Roessler \& Brewer (1946) found $\mathrm{Cl}$. botulinum type A not to require thiamine, all the toxigenic strains studied by us failed to grow in its absence. On the other hand, two strains which did not depend on thiamine for growth proved to be completely non-toxigenic. However, more work with a larger collection of strains will be needed before it can be decided whether a requirement for thiamine offers a valid criterion for differentiating toxigenic from non-toxigenic strains.

Regarding amino acid requirements, $\mathrm{Cl}$. parabotulinum type A closely resembles $\mathrm{Cl}$. sporogenes. The unusually high demand for arginine, tyrosine and phenylalanine demonstrated by Shull et al. (1949) with $C l$. sporogenes is shared by $\mathrm{Cl}$. parabotulinum type A. The only difference observed with our organisms is an ability to utilize ornithine or lysine instead of arginine.

\section{REFERENCES}

Bernheimer, A. W. (1944). Nutritional requirements and factors affecting the production of toxin of Clostridium septicum. J. exp. Med. 80, 321 .

Boyd, M. J., Logan, M. A. \& Tytell, A. A. (1948). The growth requirements of Cl. perfringens (Welchii) BP6K. J. biol. Chem. 174, 1013.

Brown, R. W., Wood, H. G. \& Werkman, C. H. (1939). Nutrient requirements of butyric acid-butyl alcohol bacteria. J. Bact. 38, 631 .

Burrows, W. (1933). Growth of Cl. botulinum on synthetic media. J. infect. Dis. $52,126$.

Donald, C., Passey, B. I. \& Swaby, R. J. (1952). A comparison of methods for removing trace metals from microbiological media. J. gen. Microbiol. 7, 211.

Elberg, S. S. \& MeYer, K. F. (1939). The nutritional requirements of Clostridium parabotulinum A. J. Bact. 37, 429.

Feeney, R. E., Mueller, J. H. \& Miller, P. A. (1943). Growth requirements of Clostridium tetani. J. Bact. 46, 563.

Findes, P. (1935). The tryptophan and 'Sporogenes Vitamin' requirements of B. botulinus. Brit. J. exp. Path. 16, 309. 
Fildes, P. \& Richardson, G. M. (1935). The amino acids necessary for the growth of Cl. sporogenes. Brit. J. exp. Path. 16, 326.

Hosoya, S. \& Kishino, S. (1925). Sulfhydryl compounds in anaerobic metabolism. Sci. rep. Gov. Inst. infect. Dis. 4, 123.

KNight, B. C. J. G. \& Fildes, P. (1933). A vitamin necessary for the growth of B. sporogenes. Its relation to auxin and other growth factors. Brit. J. exp. Path. $14,112$.

Lamanna, C. \& Lewis, C. (1946). An observation of apparent substitution of pantothenate by thiamine and choline. J. Bact. $51,398$.

Lampen, J. O. \& Pererson, W. H. (1944). The determination of $p$-aminobenzoic acid by assay with $\mathrm{Cl}$. acetobutylicum. J. biol. Chem. 153, 193.

Lewis, K. H. \& Hill, E. V. (1947). Practical media and control measures for producing highly toxic cultures of Clostridium botulinum, type A. J. Bact. 53, 213.

McDaniel, L. E., Wooliex, D. W. \& Peterson, W. H. (1939). Growth factors for bacteria. VII. Nutrient requirements of certain butyl-alcohol-producing bacteria. J. Bact. 37, 259.

Pappenheimer, Jun. A. M. (1935). The nature of the 'Sporogenes Vitamin', an essential growth factor for $\mathrm{Cl}$. sporogenes and related organisms. Biochem. $J$. 29, 2057.

Reed, L. J. \& Muench, H. (1938). A simple method of estimating fifty per cent end-points. Amer. J. Hyg. 27, 493.

Roessler, W. G. \& Brewer, C. R. (1946). Nutritional studies with Clostridium botulinum, toxin types A and B. J. Bact. 51, 571.

Rubbo, S. D. \& Gillespie, J. M. (1940). Para-amino benzoic acid as a bacterial growth factor. Nature, Lond. 146, 838.

Shull, G. M. \& Peterson, W. H. (1948). The nature of the 'Sporogenes Vitamin' and other factors in the nutrition of $\mathrm{Cl}$. sporogenes. Arch. Biochem. 18, 69.

Shull, G. M., Thoma, R. W. \& Peterson, W. M. (1949). Amino acid and unsaturated fatty acid requirements of $\mathrm{Cl}$. sporogenes. Arch. Biochem. 20, 227.

Smith, L. D. \& Douglas, H. C. (1950). Factors necessary for maximum growth of Clostridium bifermentants. J. Bact. 60, 9.

Snell, E. E., Strong, F. M. \& Peterson, W. H. (1937). Growth factors for bacteria. VI. Fractionation and properties of an accessory factor for lactic acid bacteria. Biochem. J. 31, 1789.

Thoma, R. W., Peterson, W. H. (1950). Biotin and arginine replacement in the nutrition of $\mathrm{Cl}$. sporogenes. J. Bact. 60, 39.

Weizmann, Ch. \& Rosenfeld, B. (1939). The specific nutritive requirements of $\mathrm{Cl}$. acetobutylicum (Weizmann). Biochem. J. 33, 1376.

Woods, D. D. (1952). Vitamin-B-group substances, especially folic acid and $B_{12}$, in the metabolism of micro-organisms. W. H. O. Monograph series No. 10, Genève, p. 35.

(Received 27 July 1953)

\section{ADDENDUM}

After completion of this work 8 additional strains were examined for their vitamin requirements. Seven toxigenic strains showed the typical nutritional pattern-i.e. requirement for biotin, thiamine and $p$-AB. One strain which grew in absence of thiamine, when tested under conditions as described in the text, proved to be non-toxigenic.

We are indebted to Dr H. D. Michener of the Western Regional Research Laboratory, Albany, California, U.S.A., for 7 of the strains. 